University of Nebraska - Lincoln

DigitalCommons@University of Nebraska - Lincoln

\title{
Genetic mapping of paternal sorting of mitochondria in cucumber
}

\author{
Claudia I. Calderon \\ University of Wisconsin \\ Brian S. Yandell \\ University of Wisconsin \\ Michael J. Havey \\ University of Wisconsin, mjhavey@wisc.edu
}

Follow this and additional works at: https://digitalcommons.unl.edu/usdaarsfacpub

Part of the Agricultural Science Commons

Calderon, Claudia I.; Yandell, Brian S.; and Havey, Michael J., "Genetic mapping of paternal sorting of mitochondria in cucumber" (2012). Publications from USDA-ARS / UNL Faculty. 977.

https://digitalcommons.unl.edu/usdaarsfacpub/977

This Article is brought to you for free and open access by the U.S. Department of Agriculture: Agricultural Research Service, Lincoln, Nebraska at DigitalCommons@University of Nebraska - Lincoln. It has been accepted for inclusion in Publications from USDA-ARS / UNL Faculty by an authorized administrator of DigitalCommons@University of Nebraska - Lincoln. 


\title{
Genetic mapping of paternal sorting of mitochondria in cucumber
}

\author{
Claudia I. Calderon • Brian S. Yandell • \\ Michael J. Havey
}

Received: 9 September 2011/Accepted: 31 January 2012/Published online: 21 February 2012

(C) Springer-Verlag (outside the USA) 2012

\begin{abstract}
Mitochondria are organelles that have their own DNA; serve as the powerhouses of eukaryotic cells; play important roles in stress responses, programmed cell death, and ageing; and in the vast majority of eukaryotes, are maternally transmitted. Strict maternal transmission of mitochondria makes it difficult to select for better-performing mitochondria, or against deleterious mutations in the mitochondrial DNA. Cucumber is a useful plant for organellar genetics because its mitochondria are paternally transmitted and it possesses one of the largest mitochondrial genomes among all eukaryotes. Recombination among repetitive motifs in the cucumber mitochondrial DNA produces rearrangements associated with strongly mosaic (MSC) phenotypes. We previously reported nuclear control of sorting among paternally transmitted mitochondrial DNAs. The goal of this project was to map paternal sorting of mitochondria as a step towards its eventual
\end{abstract}

Names are necessary to report factually on available data; however, the US Department of Agriculture (USDA) neither guarantees nor warrants the standard of the product, and the use of the name by USDA implies no approval of the product to the exclusion of others that may also be suitable.

Communicated by C. Quiros.

Electronic supplementary material The online version of this article (doi:10.1007/s00122-012-1812-z) contains supplementary material, which is available to authorized users.

C. I. Calderon - B. S. Yandell

Department of Horticulture, University of Wisconsin,

Madison, WI 53706, USA

M. J. Havey $(\bowtie)$

USDA/ARS, Department of Horticulture,

University of Wisconsin, Madison, WI 53706, USA

e-mail: mjhavey@wisc.edu cloning. We crossed single plants from plant introduction (PI) 401734 and Cucumis sativus var. hardwickii and produced an $\mathrm{F}_{2}$ family. A total of $425 \mathrm{~F}_{2}$ plants were genotyped for molecular markers and testcrossed as the female with MSC16. Testcross families were scored for frequencies of wild-type versus MSC progenies. Discrete segregations for percent wild-type progenies were not observed and paternal sorting of mitochondria was therefore analyzed as a quantitative trait. A major quantitative trait locus (QTL; LOD >23) was mapped between two simple sequence repeats encompassing a 459 -kb region on chromosome 3. Nuclear genes previously shown to affect the prevalence of mitochondrial DNAs (MSHI, OSB1, and RECA homologs) were not located near this major QTL on chromosome 3. Sequencing of this region from PI 401734, together with improved annotation of the cucumber genome, should result in the eventual cloning of paternal sorting of mitochondria and provide insights about nuclear control of organellar-DNA sorting.

\section{Introduction}

Plants possess DNA in the nucleus, chloroplast, and mitochondrion. For the vast majority of plants, the organellar (chloroplast and mitochondrial) DNAs are maternally transmitted; although biparental (Smith 1989; Reboud and Zeyl 1994; Zhang and Sodmergen 2003; Weihe et al. 2009) and paternal (Neale et al. 1989; Neale and Sederoff 1989; Fauré et al. 1994; Havey 1997; Havey et al. 1998; Chat et al. 1999; McCauley et al. 2005) transmissions of organellar DNAs are known. The plant mitochondrial DNA is generally much larger (367 and $570 \mathrm{~kb}$ for Arabidopsis and maize, respectively) than those of most animals or fungi ( $\sim 17 \mathrm{~kb}$ for humans and $\sim 15 \mathrm{~kb}$ for yeast) (Gillham 1994; 
Unseld et al. 1997). Plant mitochondrial DNAs can undergo intramolecular recombination to produce different gene orders among relatively closely related individuals (Fauron et al. 1995), as well as chimeric reading frames associated with cytoplasmic male sterilities (Fujii and Toriyama 2008) and variegated phenotypes (Martinez-Zapater et al. 1992; Newton 1995; Bartoszewski et al. 2004). Nuclear genes, such as MSH1, RECA, and OSBI (Abdelnoor et al. 2003; Zaegel et al. 2006; Shedge et al. 2007; Arrieta-Montiel et al. 2009); affect the generation and prevalence of specific mitochondrial-DNA variants (sublimons).

Cucumber (Cucumis sativus L.) represents a unique model plant for organellar genetics because its three genomes show different modes of transmission maternal for chloroplast, paternal for mitochondrial, and biparental for nuclear genes (Havey et al. 1998), and the plant has a very large mitochondrial genome at $\sim 1.7 \mathrm{Mb}$ (Ward et al. 1981; Alverson et al. 2011). This large mitochondrial genome is due in part to the accumulation of short repetitive sequences (Lilly and Havey 2001). Recombination among these repetitive DNAs can produce mosaic (MSC) plants, which have deformed leaves and sectors of white and green tissues (Malepszy et al. 1996; Bartoszewski et al. 2004). MSC is a valuable tool for studying mitochondrial transmission because the phenotype can be easily scored at the seedling stage (Malepszy et al. 1996; Lilly et al. 2001). We previously identified a nuclear locus, Psm for paternal sorting of mitochondria, which preferentially sorts for rare wild-type mitochondrial DNAs transmitted paternally from MSC plants (Havey et al. 2004; Al-Faifi et al. 2008). The goal of this research was to fine-map paternal sorting of mitochondria as a step towards its eventual cloning in order to understand nuclear control of mitochondrial sorting.

\section{Materials and methods}

Mapping population

A single cucumber plant (3-A) from USDA Plant Introduction 401734 (Css) was selected because it produced a relatively high frequency (79\%) of wild-type progenies when crossed as the female with MSC16. This plant was crossed as the female with a single plant of $C$. sativus var. hardwickii (Csh), a feral relative of cucumber, which produced a high frequency (>90\%) of MSC progenies in crosses with MSC16. A single $F_{1}$ plant (C10106D) was propagated by stem cuttings and propagules were self-pollinated to produce an $\mathrm{F}_{2}$ family $(\mathrm{C} 10115)$. A total of $447 \mathrm{~F}_{2}$ plants were grown in the greenhouse, self-pollinated, and testcrossed with MSC16 as the male parent. We attempted to produce more than one self and testcross family when multiple female flowers were present on individual $F_{2}$ plants. Of these $447 \mathrm{~F}_{2}$ plants, 425 were genotyped for molecular markers and used to create the genetic map.

Segregation analyses

Black spines on cucumber fruit are conditioned by a dominant allele at the $B$ locus (Pierce and Wehner 1990). Css has white and Csh has black spines and fruits from $\mathrm{F}_{2}$ plants were visually scored for spine color. For paternal sorting of mitochondria, 50-60 seeds per testcross family were sown in vermiculite and placed on a warm bench $\left(30^{\circ} \mathrm{C}\right)$ in the greenhouse for approximately 3 weeks. MSC plants possess chlorotic spots on cotyledons and leaves and grow slower relative to wild-type plants (Lilly et al. 2001). The numbers of wild-type and MSC testcross progenies were counted and overall germination calculated. To assess any effects of seed dormancy on germination and to determine the reproducibility of phenotypic scores, three different plantings of testcross families were completed. The first planting was done from spring 2008 to the spring of 2009, the second was done during summer and fall of 2009 , and the third during spring and summer 2010. Seeds sown in the second planting were preferentially from the same fruit as the first planting. When there was too little remnant seed, the seeds were planted from independent testcrosses of MSC16 to the same $\mathrm{F}_{2}$ plant. In the third planting, independent testcrosses to the same $F_{2}$ plant were evaluated.

\section{Genotyping of molecular markers}

Genomic DNA was extracted from the two parental plants and $F_{2}$ progenies as described by (Krysan 2004) with modifications. Fresh leaf tissue from young plants was placed into a 96-well plate and a 1-mm diameter stainless steel ball was added to each well. $200 \mu \mathrm{L}$ of TE $(9.5 \mathrm{mM}$ EDTA and $50 \mathrm{mM}$ Tris $\mathrm{pH}$ 9) were added; the plate was sealed and placed on a Geno Grinder 2000 shaker (GlenMills, Clifton, NJ, USA) for $2 \mathrm{~min}$ at $450 \mathrm{strokes} / \mathrm{min}$. The 96-well plate was then centrifuged for $5 \mathrm{~min}$ at $2,000 \times \mathrm{g}$. Serial dilutions of the supernatant were tested by PCR $(1 \times$ PCR buffer, $3 \mathrm{mM} \mathrm{MgCl} 2,0.2 \mathrm{mM}$ of each dNTP, $1 \mu \mathrm{M}$ of each primer, 0.5 unit of Taq polymerase) to identify the best amount for amplifications. Primers used for DNA testing were AEST25 F (GCAAAGACCAATCTTAATGT) and R (TGGGACATCATCGTTTCTGA) with PCR conditions of $3 \mathrm{~min}$ at $95^{\circ} \mathrm{C}$; followed by 35 cycles of $94^{\circ} \mathrm{C}$ for $25 \mathrm{~s}, 55^{\circ} \mathrm{C}$ for $35 \mathrm{~s}$, and $72^{\circ} \mathrm{C}$ for $20 \mathrm{~s}$; and a final extension of $3 \mathrm{~min}$ at $72^{\circ} \mathrm{C}$.

Melon (Cucumis melo L.) markers MC60 and A_23-C03 were previously shown to be linked to paternal sorting of mitochondria (Al-Faifi et al. 2008). Primers (Table 1) were designed for these genes and used to produce amplicons from DNA of the parental plants. At least 25 amplicons of 
each marker were sequenced in both directions as previously described (Al-Faifi et al. 2008). Sequences were edited and aligned using Sequencher v.4.6 (GeneCodes, Ann Arbor, MI, USA) to identify single nucleotide polymorphisms (SNPs). Melt-curve assays (Mader et al. 2008) were also used to genotype $F_{2}$ progenies. Primers were designed using LightTyper (Roche, Indianapolis, IN, USA) to produce amplicons of approximately $200 \mathrm{bp}$ with melting temperatures of $60-65^{\circ} \mathrm{C}$ (Table 1). SimpleProbes were synthesized by TIB MOLBIO (Jackson, NJ, USA) and labeled with fluorescein. The best PCR conditions for SimpleProbes were a primer ratio of 1:5 (forward:reverse) and $0.4 \mu \mathrm{M}$ of the labeled probe. Melting analysis was performed directly after PCR. SimpleProbes from marker MC60 were used to genotype the $F_{2}$ population based on the melt curve of the first negative derivative of fluorescence with respect to temperature $(-\mathrm{d} F / \mathrm{d} T)$. The iCycler $\mathrm{iQ}^{\mathrm{TM}}$ real-time PCR detection system (Bio-Rad, Hercules, CA, USA) was also used for DNA-melting analyses, using parameters of $10 \mathrm{~s}$ at $95^{\circ} \mathrm{C}, 2 \mathrm{~min}$ at $35^{\circ} \mathrm{C}$ and a temperature melting range from 35 to $75^{\circ} \mathrm{C}$ with $1^{\circ} \mathrm{C}$ increments per cycle and a hold time of $5 \mathrm{~s}$. Differential melting temperatures of alleles were used to assign a genotype to each plant.

Primers for 960 simple sequence repeats (SSR) of cucumber (Ren et al. 2009) were used in bulk segregant analysis (Michelmore et al. 1991) to identify polymorphisms associated with paternal sorting of mitochondria. Two pools of DNA were used, one containing DNAs from $15 \mathrm{~F}_{2}$ plants which produced $>90 \%$ MSC testcross progenies and the second with seven DNAs of $F_{2}$ plants which produced $>90 \%$ wild-type testcross progenies. Equal amounts of each DNA were pooled. $10 \mu \mathrm{L}$ PCR reactions were performed $(1 \times \mathrm{PCR}$ buffer, $3 \mathrm{mM} \mathrm{MgCl}$, $0.2 \mathrm{mM}$ of each dNTP, $1 \mu \mathrm{M}$ of each primer, 0.5 unit of Taq polymerase, and $20 \mathrm{ng}$ of bulked DNA) using the same cycling program as described above. Amplicons were resolved through 3\% (w/v) Super Fine Resolution (Amresco, Solon, OH, USA) agarose gels for 4-7 h, at constant voltage of 70. Markers polymorphic between the two bulks were evaluated using DNA from $425 \mathrm{~F}_{2}$ progenies and the two parental DNAs. Genotyping of polymorphic SSRs was performed using polyacrylamide gels prepared with $39 \mathrm{~mL}$ of $40 \%$ acrylamide stock, $130 \mathrm{~mL}$ of $1 \times$ TBE, $89 \mathrm{~mL}$ of $\mathrm{ddH}_{2} 0,1.82 \mathrm{~mL}$ of $10 \%$ APS, and $208 \mu \mathrm{L}$ of TEMED. 5-10 $\mu \mathrm{L}$ of PCR reactions were mixed with $2.5 \mu \mathrm{L}$ of loading dye $(0.25 \%$ bromophenol blue and $40 \%(\mathrm{w} / \mathrm{v})$ sucrose dissolved in water) and $1.25 \mu \mathrm{L}$ of a 1:100 dilution of 10,000× GelRed nucleic acid Gel Stain (Biotium, Hayward, CA, USA). Gels were run at 300 volts for $1.5 \mathrm{~h}$. Additional primer pairs (SSR_Psm5, SSR_Psm7, and SSR_Psm8 in Table 1) were designed for microsatellites between SSR06011 and SSR15124 based on the genomic sequence from cucumber line 9930 (Huang et al. 2009) using Tandem Repeat Occurrence Locator program (Castelo et al. 2002) or the SSR identification tool from the Cucurbit Genomic Database (http://www.icugi.org/).

Fragment analysis by capillary electrophoresis and meltcurve analyses were also used to genotype the $F_{2}$ family.
Table 1 Primer sequences used for genotyping of molecular markers

${ }^{\mathrm{a}}$ Fragment $=$ Capillary resolution of fragment size differences

\begin{tabular}{|c|c|c|}
\hline Primer & Genotyping method $^{\mathrm{a}}$ & Primer sequence $\left(5^{\prime}-3^{\prime}\right)$ \\
\hline MC60-F & Sequencing & GGAGCAAGAAGCTCAACACA \\
\hline MC60-R & Sequencing & TGCAATCTGCAAAATCCTGA \\
\hline MC60-F & Melt curve & TGCTTCAGGAGCATGTT \\
\hline MC60-R & Melt curve & CTGCATATCGTGCCCAA \\
\hline A_23-C03-F & Sequencing & CTGGAACACCACCAGTTCCT \\
\hline A_23-C03-R & Sequencing & GTCAGGTAGCCCAAGACAGG \\
\hline A_23-C03-F & Melt curve & GCTTTAGCACTTCCACAA \\
\hline A_23-C03-R & Melt curve & TGAAGGGGCACTTTACG \\
\hline MSH1-F & Sequencing & TAGGAGGCTGAATGGTTGCT \\
\hline MSH1-R & Sequencing & TCCCTCACTCTCCCATGTTT \\
\hline SSR_Psm5-F & Fragment & $\begin{array}{l}\text { CACGACGTTGTAAAACGACTG } \\
\text { AAGAGAAGACCCCACTGA }\end{array}$ \\
\hline SSR_Psm5-R & Fragment & $\begin{array}{l}\text { GTTTCACCCAAATAACATGAAG } \\
\text { GAGA }\end{array}$ \\
\hline SSR_Psm7-F & Fragment & $\begin{array}{l}\text { CACGACGTTGTAAAACGACTCC } \\
\text { TACCCATCTCCATGTCA }\end{array}$ \\
\hline SSR_Psm7-R & Fragment & $\begin{array}{l}\text { GTTTCCAAGAATCTTACTTTCTT } \\
\text { TGTCAATC }\end{array}$ \\
\hline SSR_Psm8-F & Fragment & $\begin{array}{c}\text { CACGACGTTGTAAAACGACTGG } \\
\text { ACAAAATCATGAAGTCATTC }\end{array}$ \\
\hline SSR_Psm8-R & Fragment & GTGCTTTATAGCGTAGAAAAACATT \\
\hline
\end{tabular}


Fluorescently labeled primers (FAM or HEX) were used for PCR amplifications to label fragments that were subsequently mixed with Geneflo 625 DNA ladder labeled with ROX (CHIMERx, Milwaukee, WI, USA) as the size standard. DNA fragments and standards are denatured with $\mathrm{Hi}-\mathrm{Di}^{\mathrm{TM}}$ Formamide (Applied Biosystems (ABI), Foster City, CA, USA) prior to loading on the ABI 3700 at the University of Wisconsin Biotechnology Center. Peaks were visualized using the Genescan software package from ABI. For melt-curves, intercalating dyes such as SybrGreen (Promega, Madison, WI, USA) or EvaGreen (Biotium, Hayward, CA, USA) were added to the master mix and the iCycler real-time detection system was used to perform the analyses.

\section{Linkage and QTL analyses}

Goodness-of-fits to the expected segregations (1:2:1 for SSRs or SNPs or 3:1 for spine color) were calculated using Microsoft (Redmond, WA, USA) Excel 2007 and detection of linkages in centiMorgans (cM) using the Kosambi mapping function were completed using Map manager QTXb20 (Manly and Olson 1999; Manly et al. 2001). Orders and recombinations among SSRs were compared to the genetic map of Ren et al. (2009).

Due to the semi-continuous distribution of the percentage of wild-type and MSC progenies, composite interval mapping (Zeng 1993, 1994; Jiang and Zeng 1995) was completed using QTL Cartographer v2.5 (Wang et al. 2010) with a walking speed of $0.5 \mathrm{cM}$ and window size from 1 to $10 \mathrm{cM}$. A maximum of five marker loci were selected as cofactors by stepwise forward regression to reduce background effects. Simple interval mapping was also completed using R/qtl for binary, two-part, normal, and non-parametric data (Broman and Sen 2009). A QTL was declared significant when its LOD score was higher than the LOD threshold calculated using 1,000 permutations for and experimental-wise (type I) error rate of $P=0.05$ (Churchill and Doerge 1994).

Evaluation of candidate genes

$M S H 1, R E C A$, and $O S B 1$ are nuclear genes that influence recombination and prevalence among mitochondrial DNAs (Martinez-Zapater et al. 1992; Abdelnoor et al. 2003; Zaegel et al. 2006; Shedge et al. 2007; Arrieta-Montiel et al. 2009). Putative homologs to these genes in the cucumber genome were identified using translated BLAST searches and their locations compared to the major QTL controlling paternal sorting of mitochondria. Primers were designed for MSH1 (Table 1), SNPs identified by sequencing amplicons as previously described, and segregations determined.

\section{Results}

Segregation of genetic markers

Cucumber has a narrow genetic background (Dijkhuizen et al. 1996; Staub et al. 2005) and a previous study revealed that the genomic region associated with paternal sorting of mitochondria was highly monomorphic in a cross between two cultivated cucumbers (PI 401734 and 'Straight 8'), with an average of one SNP every $25 \mathrm{~kb}$ of genomic sequence (Al-Faifi et al. 2008). Therefore, we developed a segregating family from more genetically diverse parents (Css and Csh). Spine color on fruits from $\mathrm{F}_{2}$ plants yielded 228 black $(B-)$ and 77 white-spined $(b b)$, fitting the expected 3:1 ratio $(P=0.921)$ (Table 2$)$.

Al-Faifi et al. (2008) previously reported that paternal sorting of mitochondria showed linkage to an RFLP revealed by CsP483 and melon markers MC60 and A_23C03. The sequence of genomic clone CsP483 (Genbank accession CC144388) showed significant similarity to sequences on chromosome 3 of cucumber (Huang et al. 2009). Bulk segregant analysis revealed two polymorphic SSRs (SSR06791 and SSR00733) also on chromosome 3

Table 2 Goodness-of-fit to observed segregations for morphological and molecular markers

\begin{tabular}{lrrrll}
\hline Marker & Maternal & \multicolumn{2}{l}{ Observed } & & \\
\cline { 3 - 6 } & & Heterozygous & Paternal & Expected & Prob. $^{2}$ \\
\hline B & 77 & 0 & 228 & $3: 1$ & 0.921 \\
SNP_MSH1 & 12 & 23 & 21 & $1: 2: 1$ & 0.096 \\
SSR21012 & 46 & 187 & 51 & $1: 2: 1$ & $0.000^{*}$ \\
SSR17264 & 68 & 165 & 81 & $1: 2: 1$ & 0.388 \\
SNP_MC60 & 85 & 141 & 73 & $1: 2: 1$ & 0.381 \\
SSR01647 & 19 & 45 & 29 & $1: 2: 1$ & 0.325 \\
A_23-C03 & 31 & 91 & 59 & $1: 2: 1$ & $0.013 *$ \\
SSR13163 & 18 & 63 & 28 & $1: 2: 1$ & 0.106 \\
SSR02856 & 52 & 110 & 61 & $1: 2: 1$ & 0.682 \\
SSR13949 & 72 & 172 & 102 & $1: 2: 1$ & 0.074 \\
SSR11397 & 15 & 32 & 35 & $1: 2: 1$ & $0.001 *$ \\
SSR11594 & 80 & 202 & 97 & $1: 2: 1$ & 0.205 \\
SSR16238 & 67 & 166 & 81 & $1: 2: 1$ & 0.320 \\
SSR21456 & 85 & 205 & 100 & $1: 2: 1$ & 0.336 \\
SSR20338 & 81 & 177 & 85 & $1: 2: 1$ & 0.800 \\
SSR06011 & 82 & 192 & 93 & $1: 2: 1$ & 0.485 \\
SSR_Psm5 & 106 & 198 & 92 & $1: 2: 1$ & 0.610 \\
SSR_Psm7 & 101 & 171 & 82 & $1: 2: 1$ & 0.294 \\
SSR_Psm8 & 44 & 106 & 40 & $1: 2: 1$ & 0.257 \\
SSR15124 & 93 & 190 & 85 & $1: 2: 1$ & 0.691 \\
SSR23177 & 108 & 201 & 64 & $1: 2: 1$ & $0.002^{*}$ \\
SSR00733 & 97 & 212 & 100 & $1: 2: 1$ & 0.743 \\
SSR06791 & 67 & 144 & 64 & $1: 2: 1$ & 0.712 \\
\hline & & & &
\end{tabular}

${ }^{a}$ Asterisk indicates poor fit to expected ratio 
(Ren et al. 2009). These two SSRs, together with 17 additional SSRs on chromosome 3 and melon markers MC60 and A_23-C03, were genotyped using DNAs from $425 \mathrm{~F}_{2}$ progenies. Three $(21012,11397$, and 23177) out of the 19 SSRs and melon marker A_23-C03 did not fit the expected 1:2:1 segregation for codominant loci; all other molecular markers fit expected segregations (Table 2).

Linkages among the SSR markers agreed closely with those previously reported by Ren et al. (2009), except for the position of two markers at the end of the linkage group (Fig. 1). We observed higher rates of recombination in our $F_{2}$ population than those reported by Ren et al. (2009); genetic linkages among markers in our map spanned $88 \mathrm{cM}$ as compared to $35 \mathrm{cM}$ in the Ren et al. (2009) map (Fig. 1). This discrepancy could be due to the relatively few (77) recombinant inbred lines used by Ren et al.
(2009), as compared to $425 \mathrm{~F}_{2}$ progenies used for our genetic map. Melon markers MC60 and A_23-C03, previously shown to be linked to paternal sorting of mitochondria in a different cross (Al-Faifi et al. 2008), were linked to these SSR markers on chromosome 3 of cucumber (Fig. 1).

Mapping of paternal sorting of mitochondria

Although we previously reported that paternal sorting of mitochondria was controlled by a single locus (Havey et al. 2004; Al-Faifi et al. 2008), non-discrete segregations were observed in the Css by Csh cross used in this study (Fig. 2). This discrepancy could be due to environmental conditions when testcrosses were made, seed dormancy from Csh (Lower and Edwards 1986), or poor germination of MSC
Fig. 1 Linkages and genetic distances in centiMorgans (cM) among markers on chromosome 3 from two segregating families of cucumber. The map on the left is from the $425 \mathrm{~F}_{2}$ progenies from Plant Introduction $401734 \times$ Cucumis sativus var. hardwickii (this study); the map on the right is from 77 recombinant inbred lines from the cross of GY14 $\times$ Cucumis sativus var. hardwickii (Ren et al. 2009). Positions of markers segregating in both families are shown by lines. Scaffolds from the genomic sequence from cucumber line 9930 (Huang et al. 2009) are shown on the right

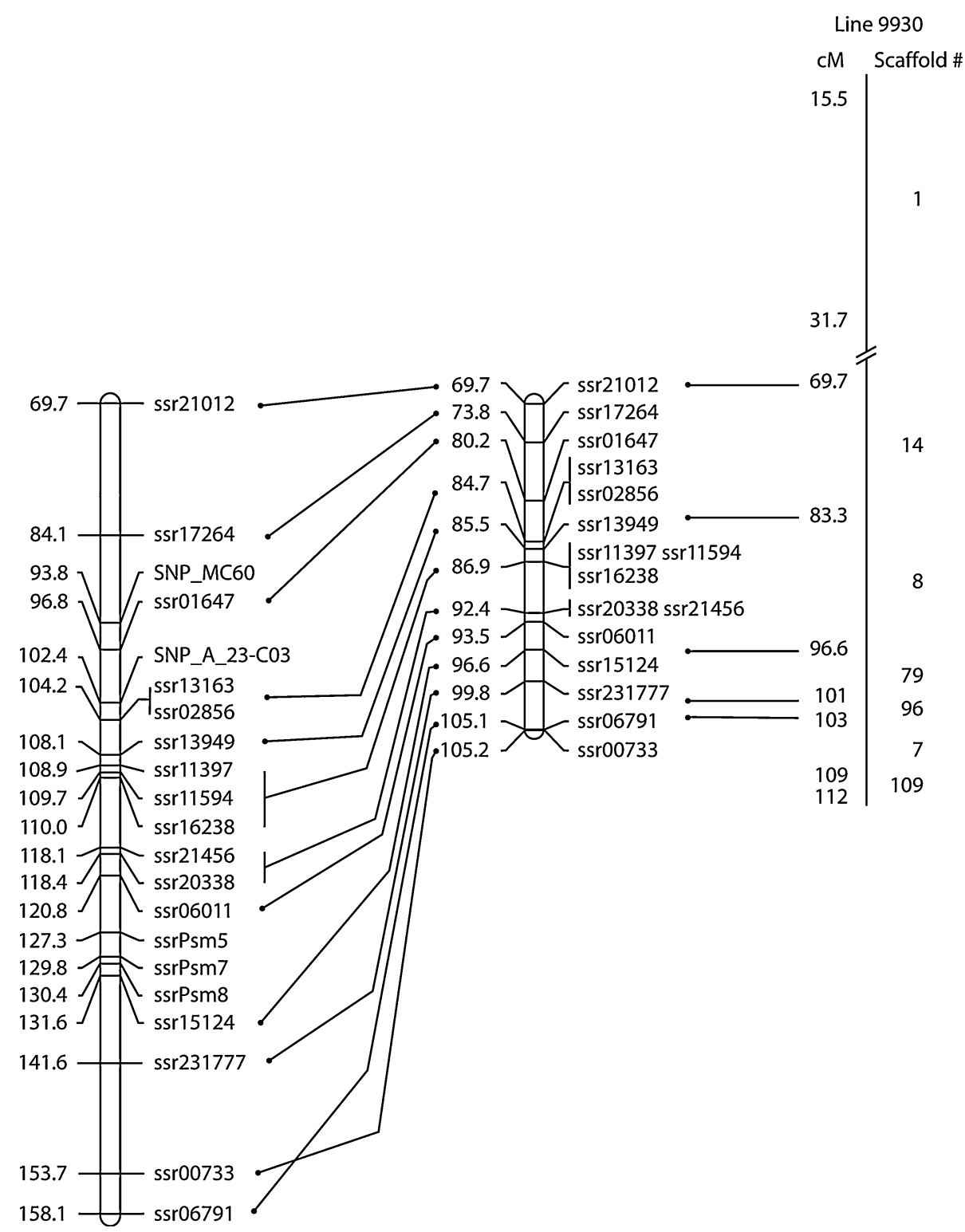




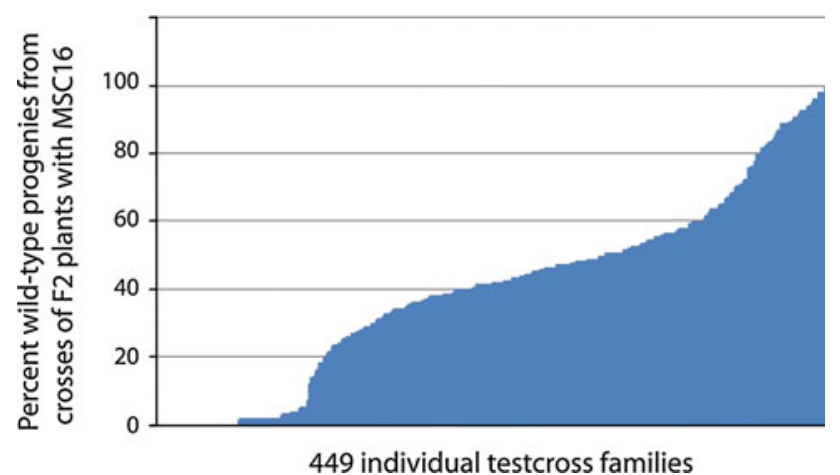

Fig. 2 Percentage of wild-type progenies ( $y$-axis) in families ( $x$-axis) from $\mathrm{F}_{2}$ female plants testcrossed with MSC16 as the male

progenies. To assess potential environmental effects on the proportion of MSC to wild-type testcross progenies, seed from independent testcrosses to the same $F_{2}$ plant were evaluated. Out of $447 \mathrm{~F}_{2}$ plants with successful testcrosses with MSC16 as the male (Supplemental Table 1), 340 had more than one fruit derived from independent testcrosses on different days. Only three (IY, O, and X) plants showed noticeably different numbers of wild-type versus MSC progenies from independent testcrosses (Supplemental Table 1). For e.g., from four independent testcrosses to $F_{2}$ plant IY, two families had 3 or $4 \%$ wild-type progenies, while the other two families had 26 or $52 \%$ wild-type progenies (Supplemental Table 1). These few differences among replicated testcross families could be due to an environmental effect on the ability of pollen to grow and successfully reach the ovule on the day the testcross was made. To assess the potential effect of seed dormancy, we planted testcross seed from the same fruit across 3 years and observed that germination significantly $(P<0.001)$ increased over time. Nevertheless, the relative proportions of MSC and wild-type progenies were consistent across time (Supplemental Table 1). Pairwise $t$ tests revealed significant differences $(P<0.001)$ between the mean germination rate of testcross families that were predominantly
MSC (mean of 68\%) compared to that from families with approximately equal numbers of wild-type and MSC progenies (mean of $76 \%$ ) or largely wild-type progenies (mean of $83 \%$ ). An overall reduction in numbers of MSC seedlings relative to wild-type supports a deleterious effect of MSC on progenies, which could increase the proportion of wild-type testcross progenies.

Because of its continuous distribution, we analyzed paternal sorting of mitochondria as a quantitative trait using the mean proportion of wild-type testcross progenies across all plantings of seed from the same fruit as well as seed from independent testcrosses. Interval mapping using QTL cartographer, as well as different quantitative models (binary, two-part, normal, and non-parametric) in R/qtl, revealed a highly significant QTL (LOD $>23$ ) between SSRs 21456 and 06011 on chromosome 3 (Fig. 3). This major QTL was placed approximately $25 \mathrm{cM}$ from melon marker MC60, closely agreeing with the $17 \mathrm{cM}$ between MC60 and Psm previously reported by Al-Faifi et al. (2008). The genetic distance between SSRs 21456 and 06011 was $2.7 \mathrm{cM}$ and both SSRs have been assigned to sequence scaffold 00008 of cucumber line 9930 (Huang et al. 2009).

\section{Evaluation of candidate genes}

Nuclear genes, such as MSH1, RECA, and OSB1 affect recombination and prevalence among plant mitochondrial DNAs (Abdelnoor et al. 2003; Zaegel et al. 2006; Shedge et al. 2007; Arrieta-Montiel et al. 2009). These genes could also control the predominance of specific mitochondrial DNAs in the developing embryo. Putative cucumber homologs of MSH1, REC1A, REC2A, REC3A, and OSB1 were identified by translated searches and assigned to scaffolds 000001, 000366, 000031, 000040, and 000109, respectively, of cucumber 9930 (Huang et al. 2009). Of these, scaffolds 000001 (MSH1) and 000109 (OSB1) have been assigned to chromosome 3 of cucumber; however,
Fig. 3 LOD values ( $y$-axis) from QTL cartographer for percent wild-type progenies from crosses of MSC16 as the male to $F_{2}$ progenies. Linkages of molecular markers are shown on $x$-axis. Horizontal line shows LOD threshold from permutation analysis

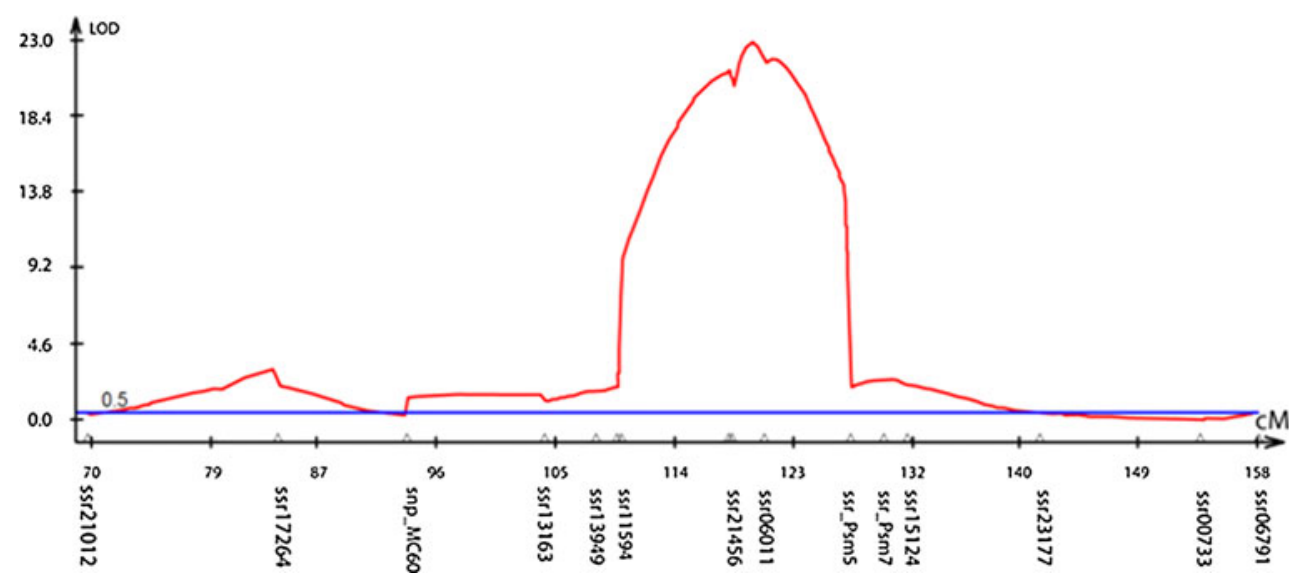


scaffold 000001 is approximately $60 \mathrm{cM}$ and scaffold 000109 is located about $20 \mathrm{cM}$ from scaffold 00008 where the major QTL for paternal sorting of mitochondria was placed. Single nucleotide polymorphisms in $\mathrm{MSH} 1$ (Table 2) confirmed that this gene segregated independently from the genetic region carrying the major QTL controlling paternal sorting of mitochondria, agreeing with Al-Faifi et al. (2008).

\section{Discussion}

Although we previously reported that paternal sorting of mitochondria was controlled by the single locus Psm (Havey et al. 2004; Al-Faifi et al. 2008), non-discrete segregations were observed in this study (Fig. 2). This discrepancy could be due to a combination of reduced viability of MSC progenies, seed dormancy, or environmental effects during fertilization and embryo development. Nevertheless, our results reveal that paternal sorting of mitochondria is controlled by a major QTL (LOD >23) on chromosome 3. This major QTL showed linkage to marker MC60 in agreement with the previous segregation analysis of Al-Faifi et al. (2008) using a different cross. Therefore, we are confident that the major QTL mapped using the Css by Csh cross is the same as the Psm locus described by Havey et al. (2004) and Al-Faifi et al. (2008).

Nuclear genes, such as MSH1, REC1A, REC 2A, REC3A, and $O S B 1$, affect recombination among and the prevalence of specific mitochondrial DNAs (Arrieta-Montiel et al. 2009). The plant MutS homolog 1 (MSH1) gene is targeted to the organelles and is involved in mismatch repair (Xu et al. 2011). In Arabidopsis, mutations in MSH1 are associated with accumulation of rearranged mitochondrial DNAs and variegated green tissues (Martinez-Zapater et al. 1992). Mutations in the RECA genes result in illegitimate recombination among mitochondrial DNAs (Odahara et al. 2009). OSBs are plant-specific single-stranded DNA-binding proteins targeted to organelles that control stoichiometries of different mitochondrial DNAs after recombination events (Zaegel et al. 2006; Maréchal and Brisson 2010). Importantly, the region on chromosome 3 that controls paternal sorting of mitochondria does not carry cucumber homologs of the $M S H 1, R E C A$, and OSB1 genes, indicating that paternal sorting of mitochondria in cucumber may provide new and unique insights about nuclear control of mitochondrial sorting.

The 2.7-cM region between SSRs 21456 and 06011 corresponds to $459 \mathrm{~kb}$ based on the genomic sequence of cucumber GY14 on Phytozome v 5.0 (http://www.phytozome.net/). Database searches revealed at least 69 putative genes supported by cDNAs in this genomic region (Supplemental Table 2). Our research will now focus on sequencing through this genomic region in PI 401734 to identify and evaluate candidate genes, in order to better understand nuclear control of mitochondrial-DNA sorting.

Acknowledgments This work was supported by the USDA-ARS and the Ruth Dickie Scholarship from the University of Wisconsin

\section{References}

Abdelnoor RV, Yule R, Elo A, Christensen AC, Meyer-Gauen G, Mackenzie SA (2003) Substoichiometric shifting in the plant mitochondrial genome is influenced by a gene homologous to MutS. Proc Natl Acad Sci (USA) 100:5968-5973

Al-Faifi S, Meyer J, Garcia-Mas J, Monforte A, Havey M (2008) Exploiting synteny in Cucumis for mapping of Psm: a unique locus controlling paternal mitochondrial sorting. Theor Appl Genet 117:523-529

Alverson AJ, Rice DW, Dickinson S, Barry K, Palmer JD (2011) Origins and recombination of the bacterial-sized multichromosomal mitochondrial genome of cucumber. Plant Cell 23:24992513

Arrieta-Montiel MP, Shedge V, Davila J, Christensen AC, Mackenzie SA (2009) Diversity of the Arabidopsis mitochondrial genome occurs via nuclear-controlled recombination activity. Genetics 183:1261-1268

Bartoszewski G, Malepszy S, Havey MJ (2004) Mosaic (MSC) cucumbers regenerated from independent cell cultures possess different mitochondrial rearrangements. Curr Genet 45:45-53

Broman KW, Sen S (2009) A guide to QTL mapping with R/qtl. Springer, New York

Castelo AT, Martins W, Gao GR (2002) TROLL-tandem repeat occurrence locator. Bioinformatics 18:634-636

Chat J, Chalak L, Petit RJ (1999) Strict paternal inheritance of chloroplast DNA and maternal inheritance of mitochondrial DNA in interspecific crosses of kiwifruit. Theor Appl Genet 99:314-322

Churchill GA, Doerge RW (1994) Empirical threshold values for quantitative trait mapping. Genetics 138:963-971

Dijkhuizen A, Kennard WC, Havey MJ, Staub JE (1996) RFLP variation and genetic relationships in cultivated cucumber. Euphytica 90:79-87

Fauré S, Noyer J-L, Carreel F, Horry J-P, Bakry F, Lanaud C (1994) Maternal inheritance of chloroplast genome and paternal inheritance of mitochondrial genome in bananas (Musa acuminata). Curr Genet 25:265-269

Fauron CM-R, Moore B, Casper M (1995) Maize as a model of higher plant mitochondrial genome plasticity. Plant Sci 112:11-32

Fujii S, Toriyama K (2008) Genome barriers between nuclei and mitochondria exemplified by cytoplasmic male sterility. Plant Cell Physiol 49:1484-1494

Gillham NW (1994) Organelle genes and genomes. Oxford University Press, New York

Havey MJ (1997) Predominant paternal transmission of the mitochondrial genome in cucumber. J Hered 88:232-235

Havey MJ, McCreight JD, Rhodes B, Taurick G (1998) Differential transmission of the Cucumis organellar genomes. Theor Appl Genet 97:122-128

Havey MJ, Park YH, Bartoszewski G (2004) The Psm locus controls paternal sorting of the cucumber mitochondrial genome. J Hered 95:492-497

Huang S, Li R, Zhang Z, Li L, Gu X, Fan W, Lucas WJ, Wang X, Xie B, Ni P, Ren Y, Zhu H, Li J, Lin K, Jin W, Fei Z, Li G, Staub J, 
Kilian A, van der Vossen EAG, Wu Y, Guo J, He J, Jia Z, Ren Y, Tian G, Lu Y, Ruan J, Qian W, Wang M, Huang Q, Li B, Xuan Z, Cao J, Asan WuZ, Zhang J, Cai Q, Bai Y, Zhao B, Han Y, Li Y, Li X, Wang S, Shi Q, Liu S, Cho WK, Kim J-Y, Xu Y, Heller-Uszynska K, Miao H, Cheng Z, Zhang S, Wu J, Yang Y, Kang H, Li M, Liang H, Ren X, Shi Z, Wen M, Jian M, Yang H, Zhang G, Yang Z, Chen R, Liu S, Li J, Ma L, Liu H, Zhou Y, Zhao J, Fang X, Li G, Fang L, Li Y, Liu D, Zheng H, Zhang Y, Qin N, Li Z, Yang G, Yang S, Bolund L, Kristiansen K, Zheng H, Li S, Zhang X, Yang H, Wang J, Sun R, Zhang B, Jiang S, Wang J, Du Y, Li S (2009) The genome of the cucumber, Cucumis sativus $\mathrm{L}$. Nat Genet 41:1275-1281

Jiang C, Zeng ZB (1995) Multiple trait analysis of genetic mapping for quantitative trait loci. Genetics 140:1111-1127

Krysan P (2004) Ice-Cap. A high-throughput method for capturing plant tissue samples for genotype analysis. Plant Physiol 135:1162-1169

Lilly J, Havey M (2001) Small, repetitive DNAs contribute significantly to the expanded mitochondrial genome of cucumber. Genetics 159:317-328

Lilly J, Bartoszewski G, Malepszy S, Havey M (2001) A major deletion in the cucumber mitochondrial genome sorts with the MSC phenotype. Curr Genet 40:144-151

Lower RL, Edwards MD (1986) Cucumber breeding. In: Basset MJ (ed) Breeding vegetable crops. AVI Publishing, Westport, pp 173-207

Mader E, Lukas B, Novak J (2008) A strategy to setup codominant microsatellite analysis for high-resolution-melting-curve-analysis (HRM). BMC Genet 9:69

Malepszy S, Burza W, Smiech M (1996) Characterization of a cucumber (Cucumis sativus L.) somaclonal variant with paternal inheritance. J Appl Genet 37:65-78

Manly KF, Olson JM (1999) Overview of QTL mapping software and introduction to map manager QT. Mamm Genome 10:327-334

Manly KF, Cudmore RH Jr, Meer JM (2001) Map Manager QTX, cross-platform software for genetic mapping. Mamm Genome 12:930-932

Maréchal A, Brisson N (2010) Recombination and the maintenance of plant organelle genome stability. New Phytol 186:299-317

Martinez-Zapater JM, Gil P, Capel J, Somerville CR (1992) Mutations at the Arabidopsis CHM locus promote rearrangements of the mitochondrial genome. Plant Cell 4:889-899

McCauley DE, Bailey MF, Sherman NA, Darnell MZ (2005) Evidence for paternal transmission and heteroplasmy in the mitochondrial genome of Silene vulgaris, a gynodioecious plant. Heredity 95:50-58

Michelmore RW, Paran I, Kesseli RV (1991) Identification of markers linked to disease-resistance genes by bulked segregant analysis: a rapid method to detect markers in specific genomic regions by using segregating populations. Proc Natl Acad Sci (USA) 88:9828-9832

Neale DB, Sederoff RR (1989) Paternal inheritance of chloroplast DNA and maternal inheritance of mitochondrial DNA in loblolly pine. Theor Appl Genet 77:212-216

Neale DB, Marshall KA, Sederoff RR (1989) Chloroplast and mitochondrial DNA are paternally inherited in Sequoia sempervirens D. Don Endl. Proc Natl Acad Sci 86:9347-9349
Newton KJ (1995) Aberrant growth phenotypes associated with mitochondrial genome rearrangements in higher plants. In: Levings CS III, Vasil IK (eds) The molecular biology of plant mitochondria. Kluwer, Boston, pp 585-596

Odahara M, Kuroiwa H, Kuroiwa T, Sekine Y (2009) Suppression of repeat-mediated gross mitochondrial genome rearrangements by RecA in the moss Physcomitrella patens. Plant Cell 21:11821194

Pierce LK, Wehner TC (1990) Review of genes and linkage groups in cucumber. HortScience 25:605-615

Reboud X, Zeyl C (1994) Organelle inheritance in plants. Heredity $72: 132-140$

Ren Y, Zhang Z, Liu J, Staub JE, Han Y, Cheng Z, Li X, Lu J, Miao H, Kang H, Xie B, Gu X, Wang X, Du Y, Jin W, Huang S (2009) An integrated genetic and cytogenetic map of the cucumber genome. PLoS one 4:e5795

Shedge V, Arrieta-Montiel M, Christensen AC, Mackenzie SA (2007) Plant mitochondrial recombination surveillance requires unusual RecA and MutS homologs. Plant Cell 19:1251-1264

Smith SE (1989) Biparental inheritance of organelles and its implications in crop improvement. Plant Breed Rev 6:361-393

Staub JE, Chung SM, Fazio G (2005) Conformity and genetic relatedness estimation in crop species having a narrow genetic base: the case of cucumber (Cucumis sativus L.). Plant Breeding 124:44-53

Unseld M, Marienfeld JR, Brandt P, Brennicke A (1997) The mitochondrial genome of Arabidopsis thaliana contains 57 genes in 366,924 nucleotides. Nat Genet 15:57-61

Wang S, Basten CJ, Zeng ZB (2010) Windows QTL Cartographer 2.5, Department of Statistics, North Carolina State University, Raleigh, NC

Ward B, Anderson R, Bendich A (1981) The mitochondrial genome is large and variable in a family of plants (Cucurbitaceae). Cell 25:793-803

Weihe A, Apitz J, Pohlheim F, Salinas-Hartwig A, Börner T (2009) Biparental inheritance of plastidial and mitochondrial DNA and hybrid variegation in Pelargonium. Mol Genet Genomics 282:587-593

Xu Y-Z, Arrieta-Montiel M, Virdi K, Paula W, Widhaim J, Basset G, Davila J, Elthon T, Elowsky C, Sato S, Clemente T, MacKenzie S (2011) MutS homolog1 is a nucleoid protein that alters mitochondrial and plastid properties and plant response to high light. Plant Cell 23:3426-3441

Zaegel V, Guermann B, Le Ret M, Andres C, Meyer D, Erhardt M, Canaday J, Gualberto JM, Imbault P (2006) The plant-specific ssDNA binding protein OSB1 is involved in the stoichiometric transmission of mitochondrial DNA in Arabidopsis. Plant Cell 18:3548-3563

Zeng Z-B (1993) Theoretical basis for separation of multiple linked gene effects in mapping quantitative trait loci. Proc Natl Acad Sci 90:10972-10976

Zeng ZB (1994) Precision mapping of quantitative trait loci. Genetics 136:1457-1468

Zhang Q, Sodmergen (2003) Cytological evidence for preservation of mitochondrial and plastid DNA in the mature generative cells of Chlorophytum spp. (Liliaceae). Protoplasma 221:211-216 